\title{
"Faz isso, faz aquilo, mas eu tô caindo..." - Compreendendo a Doença de Chron
}

\author{
"DO THIS, DO THAT, BUT I'M FALLING DOWN..." - UNDERSTANDING CHRON'S DISEASE \\ "HAZ ESO, HAZ AQUELLO, MAS YO ESTOY CAYENDO..." \\ - COMPRENDIENDO LA ENFERMEDAD DE CHRON
}

Andrea Castelli', Maria Júlia Paes da Silva²

\section{RESUMO}

Buscando compreender o significado e o impacto da doença de Chron na vida de seu portador, desenvolvemos este estudo, de natureza qualitativa, optando pela História Oral de Vida como referencial metodológico, tendo como base filosófica a corrente monista, advinda de Hipócrates, em que a prática médica tem por objeto a pessoa doente em sua totalidade, levando em conta seu temperamento e a sua história. A terapêutica deve restabelecer a harmonia da pessoa com seu ambiente e consigo mesma, trata-se de uma medicina integradora e dinâmica, que corresponde aos primórdios da medicina psicossomática. O estudo da doença de Chron, por meio da compreensão psicossomática, permitiu que analisássemos os sintomas, não como corpos estranhos a serem erradicados, mas como mensageiros de um apelo a ser compreendido. Por intermédio deles, pode ser resgatada a história de um indivíduo que, se conscientemente vivida e analisada, permite o desenvolvimento até níveis mais evoluídos de entendimento.

\section{DESCRITORES}

Medicina psicossomática.

Síndrome do intestino irritável/ enfermagem.

Pesquisa qualitativa.

\section{ABSTRACT}

This qualitative study was developed as an effort to understand the meaning and the impact of Chron's Disease on the carrier's life, opting for Life Oral History as the methodological reference and having as a base Hippocrates' monist philosophical school, for which the medical practice focuses on the sick person in his/her totality, taking into consideration his/her temperament and background. The therapeutics must reestablish the person's harmony with his/her environment and with himself/ herself. It is an integrative, dynamic medicine that corresponds to the beginnings of psychosomatic medicine. The studies on Chron's Disease, through psychosomatic understanding, made possible to analyze the symptoms not as alien bodies to be eradicated, but as messengers of an appeal to be understood. Through them, the person's history can be recovered, which makes possible the development to more advanced levels of understanding if it is experienced and analyzed consciously.

\section{KEY WORDS}

Psychosomatic medicine. Bowel irritable syndrome/ nursing.

Qualitative research.

\section{RESUMEN}

Buscando comprender el significado y el impacto de la Enfermedad de Chron en la vida de su portador, desarrollamos este estudio, de naturaleza cualitativa, optando por la Historia Oral de Vida como referencial metodológico, y teniendo como base filosófica la corriente monista, advenida de Hipócrates, donde la práctica médica tiene por objeto a la persona enferma en su totalidad, teniendo en cuenta su temperamento y su historia. La terapéutica debe restablecer la armonía de la persona con su ambiente y consigo misma y se trata de una medicina integradora y dinámica, que corresponde a los inicios de la medicina psicosomática. El Estudio de la enfermedad de Chron, por medio de la comprensión psicosomática, permitió que analizásemos los síntomas, no como cuerpos extraños a ser erradicados, mas como mensajeros de un apelo a ser comprendido. Por intermedio de ellos, puede ser rescatada la historia de un individuo que, si conscientemente vivida y analizada, permite el desarrollo hasta niveles más evolucionados de entendimiento.

\section{DESCRIPTORES}

Medicina psicosomática.

Síndrome del colon irritable/ enfermería.

Investigación cualitativa.

\author{
1 Enfermeira. Especia- \\ lista em Medicina \\ Comportamental \\ pela UNIFESP. \\ andreacasteli@ \\ yahoo.com.br \\ 2 Enfermeira. \\ Professora Titular \\ Associada do Depar- \\ tamento de Enferma- \\ gem Médico-Cirúrgica \\ da Escola de Enfer- \\ magem da Universi- \\ dade de São Paulo. \\ juliaps@usp.br
}


Contra o positivismo, que pára diante dos fenômenos e diz: há apenas fatos, eu digo: ao contrário, fatos é o que não há; só há interpretações. (Nietzsche, de um dos fragmentos noturnos)

\section{INTRODUÇÃO}

Desde o início da história da Medicina, duas correntes complementares divergem quanto à concepção de doença e, conseqüentemente, quanto à natureza da prática médica. A primeira, monista, vem de Hipócrates (séc. VI aC) e da escola de Cós, e tem por objeto a pessoa doente em sua totalidade; leva em conta o temperamento da pessoa e sua história; a doença é vista como uma relação global da pessoa a um distúrbio (interno ou externo), envolvendo corpo e espírito; a terapêutica deve restabelecer a harmonia da pessoa com seu ambiente e consigo mesma e trata-se de uma medicina integradora e dinâmica, que corresponde aos primórdios da medicina psicossomática $^{(1)}$.

A segunda corrente, dualista, vem de Galeno (séc I aC) e da escola de Cnide, e tem por objeto a doença, que é vista como algo autônomo em relação ao portador; é autenticada por uma lesão anatomoclínica; predominou sobre a corrente hipocrática na era de Pasteur com as descobertas das etiologias específicas das infecções, sob a forma de agentes patogênicos específicos. A terapêutica con-

\section{Por ser uma abordagem integrativa da pessoa, 0 profissional que se utiliza da psicossomática vai além da realidade física da doença, sem no entanto, negá-la.} siste em localizar a doença no corpo e extirpá-la, se possível. Trata-se de uma medicina compartimentada e mecanicista, que corresponde aos primórdios da medicina cartesiana e reducionista, a base da medicina convencional da atualidade ${ }^{(1)}$.

Este trabalho tem como base filosófica e conceitual a primeira corrente. Nessa concepção, o saber reconhecer o subjetivo existe para ampliar e fortalecer os recursos diagnósticos e terapêuticos baseados em evidências, e nunca para substituí-los. Pressupõe-se que tenhamos adquirido boa capacitação nos planos teórico-técnico e emocional, para manter uma postura que favoreça a criação do vínculo e um interesse investigativo.

O presente estudo teve início em uma clínica cirúrgica de um hospital escola da cidade de São Paulo, local onde se encontram patologias diversas, desde as mais comuns como colecistite, até aquelas menos freqüentes como Síndrome de Furnier, entre outras. Nesse serviço, trabalha-se com 3 grupos diferenciados de clientes: os provenientes da comunidade Butantã, docentes e funcionários da USP São Paulo e dos Campus do interior.

Dentre tantas pessoas submetidas a procedimentos cirúrgicos e internadas nesse hospital, uma delas, em especial, nos chamou a atenção. Um homem, 43 anos, docente da Uni- versidade do campus do interior, Doutor em Veterinária. Uma pessoa que, pelo fato de ter um grau de instrução elevado, possui boa capacidade de expressão, ótimo esclarecimento sobre a sua patologia e seu prognóstico, entende que o desenvolvimento de sua patologia é resultado das escolhas que fez durante a vida, e que o fato de ser esclarecido sobre ela, pouco contribuiu para a remissão dos efeitos da doença e de seu sofrimento. Ele é portador da Doença de Chron.

O interesse em desenvolver esse estudo surgiu da curiosidade em saber o porquê de cada indivíduo desenvolver um tipo diferente de patologia, ou melhor, qual a relação entre a patologia desenvolvida e o modo de vida de cada indivíduo.

\section{REVISÃO DA LITERATURA}

\section{Psicossomática e o processo de formação da doença}

O termo psicossomática surgiu a partir do século passado, quando Heinroth criou as expressões psicossomática (1918) e somatopsíquica (1928) distinguindo os dois tipos de influência e as duas diferentes direções. Contudo, o movimento só se consolidou em meados deste século com Alexander e a Escola de Chicago $^{(2)}$.

Por ser uma abordagem integrativa da pessoa, o profissional que se utiliza da psicossomática vai além da realidade física da doença, sem no entanto, negá-la. Agrega aos saberes médicos vinculados à metodologia das Ciências Naturais, todo um conhecimento que deriva das Ciências Humanas e Sociais, propiciando uma visão integrativa, que tende a afastar o profissional do reducionismo (biologismo, psicologismo, sociologismo $)^{(2)}$.

Na atualidade, a Psicossomática refere-se ao estudo da pessoa como ser histórico. É o estudo das relações mente corpo com ênfase na explicação psicológica da patologia somática, uma proposta de assistência integral e uma transcrição para a linguagem psicológica dos sintomas corporais ${ }^{(3)}$.

Para que se entenda o processo da formação da doença, é importante o entendimento do desencadeamento do estresse e da doença de adaptação. A todo instante o nosso organismo faz movimentos de adaptação. Quando o organismo é exposto a um estímulo percebido como ameaçador, seja ele físico, químico, biológico ou psicossocial, apresenta a tendência a responder de forma uniforme e inespecífica, anatômica e fisiologicamente. A esse conjunto de reações dá-se o nome de Síndrome geral da adaptação. Ela consiste em 3 fases: reação de alarme, resistência e fase de exaustão.

A fase da reação de alarme é caracterizada por descargas adrenérgicas da medula da supra renal e noradrenalina, em fibras pós ganglionares. Paralelamente, aciona-se o eixo 
hipotálamo-hipófise-supra renal e noradrenalina que desencadeia respostas mais lentas e prolongadas. O estímulo agudo provoca secreção do hormônio corticotrófico, que por sua vez determina a liberação de ACTH da adeno hipófise, que desencadeia a síntese e secreção de glicocorticóides pelo córtex da supra renal. Estabelece-se, então, um mecanismo de feedback negativo com os glicocorticóides atuando sobre o eixo hipotálamo-hipofisário. Se os agentes estressantes desaparecem, tais reações tendem a regredir; no entanto, se o organismo é obrigado a manter seu esforço de adaptação, entre em uma nova fase, a de resistência, que se caracteriza basicamente pela reação de hiperatividade córtico supra renal, sob mediação diencéfalo-hipofisária, com aumento do córtex da supra renal, atrofia do baço e de estruturas linfáticas, leucocitose, diminuição de eosinófilos e ulcerações. Se os estímulos estressores continuarem a agir, ou se tornarem repetitivos, a resposta se mantém, mas com duas características: diminuição da amplitude e antecipação das respostas. Poderá, ainda, haver falha nos mecanismos de defesa, com desencadeamento da terceira fase, a de exaustão, com dificuldade na manutenção dos mecanismos adaptativos, perda de reservas e morte ${ }^{(4-5)}$.

Se a reação do agressor for muito intensa ou se o agente do estresse for muito potente e/ou prolongado, poderá haver, como conseqüência, doença ou maior predisposição ao aparecimento dela. O perigo parece ser maior quando a energia mobilizada pelo estresse não pode ser consumida. Geralmente, doenças de adaptação são conseqüências do excesso de hostilidade ou reações de submissão. Além disso, a possibilidade de que o organismo contenha memória afetiva (sistema límbico e hipotálamo conectados com o córtex) de situações de estresse anteriores perpetua o potencial nocivo ${ }^{(3)}$.

O sintoma deve tornar-se supérfluo e não ser impedido de manifestar-se. Mas para isso, também é preciso desviar nosso olhar do sintoma e examinar tudo com maior profundidade, a fim de compreendermos para o quê o sintoma está apontando. A doença é um estado do ser humano que indica que sua consciência não está mais em ordem, ou seja, sua consciência registra que não há mais harmonia. Essa perda de equilíbrio interior se manifesta no corpo como um sintoma, que nada mais é que um sinal e um transmissor de informação, pois com o seu aparecimento, ele interrompe o fluxo da nossa vida e nos obriga a prestar atenção ${ }^{(6)}$.

\section{Fisiopatologia da doença de Chron}

A Doença de Chron foi descrita em 1932 por Chron, Ginzburg e Oppenheimer, como uma patologia caracterizada por um processo inflamatório crônico, transmural, que atinge todo o tubo digestivo, sendo o íleo distal e o cólon as áreas mais afetadas. Acomete igualmente ambos os sexos, tem maior incidência em adultos jovens (25-45 anos) e brancos, e a incidência entre irmãos é 30 vezes superior ${ }^{(7)}$.

De etiologia desconhecida, porém dos possíveis fatores que influenciam na etiologia e exacerbação das doenças inflamatórias intestinais, o infeccioso, o genético, o imunológico e o emocional ou sociopsicossomático têm sido considerados mais importantes ${ }^{(8)}$. O fator psicológico tem sido sugerido como fator etiológico. Segundo as autoras, muitos indivíduos com doenças inflamatórias intestinais são tidos como dependentes ou perfeccionistas passivos e ansiosos por agradar. Os comportamentos para lidar com essa situação são geralmente inadequados e podem incluir reclusão, negação e repressão( ${ }^{(9)}$.

Tem caráter imprevisível, variando com o tempo de evolução e o local macroscópico de acometimento. Pode apresentar períodos de exacerbação e remissão não relacionados a quaisquer fatos identificáveis. A formação de fístulas, fissuras e abcessos ocorre à medida que a inflamação se estende no peritôneo. Granulomas ocorrem na metade dos casos; o início dos sintomas é incidioso, com notável dor abdominal e diarréia não aliviadas à defecação; o excesso de peristaltismo causa cãimbras, que por sua vez limita a ingesta alimentar, ocasionando diminuição do peso, má nutrição e anemia secundária. As úlceras que se formam no interior da membrana intestinal levam à enterorragia com odor característico, ocasionado pela presença de pus. Pode apresentar manifestações extra-intestinais articulares, urinárias, dermatológicas, hepáticas e oculares ${ }^{(7)}$.

O diagnóstico da doença de Chron é feito através de imagens radiográficas (na fase aguda), estudo radiológico contrastado, exames endoscópicos (colonoscopia e endoscopia) e exames de diagnóstico por imagem (tomografia e ultrassonografia). O diagnóstico diferencial é feito com a retocolite ulcerativa. O tratamento pode ser clínico (uso de antiinflamatórios corticoesteróides) ou cirúrgico (ressecção do segmento acometido); mas cabe ressaltar que, diferente da retocolite ulcerativa, a ressecção do segmento acometido não regride a doença por completo, somente a sintomatologia causada pelo sofrimento intestinal afetado ${ }^{(7)}$.

Chamou-nos atenção também, após revisão bibliográfica sobre a patologia, que ela acomete geralmente uma população de nível cultural elevado. Segundo um estudo realizado na Disciplina de Coloproctologia do Hospital das Clínicas da Faculdade de Medicina da Universidade de São Paulo (HCFMUSP), o grau de instrução dos pacientes portadores de Doença de Chron era superior aos deferidos pelo IBGE (19,3\% da população brasileira era analfabeta em 1987, contra $6,4 \%$ da população estudada); 23 pacientes cursavam ou haviam completado o curso superior (o que correspondia a $16 \%$ do total) ${ }^{(10)}$.

São inúmeras as conseqüências que uma doença crônica acarreta na vida de seus portadores. Atualmente, maior atenção têm sido dedicada à adaptação psicossocial de indivíduos que convivem com doenças de longa duração, cujas etiologias permanecem duvidosas e os tratamentos insatisfatórios sob o ponto de vista da cura ${ }^{(11)}$. 
Especificamente na área de coloproctologia, o IBDQ Inflammatory Bowel Disease Questionnaire - tem sido utilizado como instrumento específico para avaliação da qualidade de vida de pacientes portadores de Doenças Inflamatórias Intestinais. Após aplicação de testes estatísticos de validade, confiabilidade e responsividade, os autores obtiveram evidências de que os efeitos adversos causados pela doenças não foram relativos somente à inflamação intestinal, extraintestinal e suas complicações, mas também, ao impacto na auto-imagem, empregabilidade, funções psicossociais, relacionamentos familiares, amizades e função sexual ${ }^{(12-13)}$. Pesquisa com 40 pacientes portadores de doenças inflamatórias intestinais, sendo 20 deles portadores de retocolite ulcerativa e 20 portadores de Doença de Chron, concluiu que esses pacientes quando falam de si, falam do corpo. A percepção da sensação somática parece ser a única forma de reconhecimento de sua identidade singular. Por isso, falar de si de outro modo é encontrar-se diante um vazio ${ }^{(11)}$.

\section{METODOLOGIA}

Buscando compreender o significado e o impacto da Doença de Chron na vida de seu portador, desenvolvemos este estudo, de natureza qualitativa, na Clínica Cirúrgica de um hospital universitário da cidade de São Paulo, optando pela História Oral de Vida como referencial metodológico.

A história oral de vida como método de coleta de dados é um recurso usado para elaboração de documentos e estudos referentes à experiência social de pessoas e grupos. Apresentase como forma de captação de experiências de pessoas dispostas a falar sobre aspectos de sua vida. Sua base é o depoimento gravado que objetiva um projeto de estudos determinado previamente, e que orienta e organiza a pesquisa. É o retrato oficial do depoente; desse modo, a verdade está na versão oferecida pelo narrador, que é soberano para revelar ou ocultar casos, situações e pessoas. Há três modalidades de história oral - de vida, temática e tradição oral. Todas elas dependem de entrevistas com pessoas que estão com suas faculdades mentais em boas condições e se apresentam para dar depoimento ${ }^{(14)}$.

A História Oral de Vida permite a compreensão de um fenômeno em sua complexidade e especificidade, pois refere-se a narrativa do conjunto da experiência de vida de uma pessoa, que encadeia sua história, segundo sua vontade e sendo soberana nas suas revelações. É constituída de um projeto elaborado, composto por tema, justificativa (que inclui objetivos), definição da colônia, formação de rede, entrevista, transcrição, conferência, uso e arquivamento ${ }^{(15)}$.

A entrevista possui degraus, a saber: pré-entrevista, entrevista e pós entrevista. Na pré-entrevista, estabelece-se o local, data e hora do encontro. A entrevista pode ser única ou múltipla, diretivas ou não, longas ou breves. No ato da gravação deve ficar registrado que a entrevista terá uma conferência e que nada será publicado sem autorização prévia do colaborador. A pós entrevista é a etapa que segue a realização da entrevista ou das entrevistas. Nesse período se dá a transcrição, cujo objetivo visa dar visibilidade ao caso tematizado ou à história narrada.

Nas três entrevistas ocorridas, foi respeitada a forma utilizada pelo colaborador para construir sua narrativa, na tentativa de captar a sua interpretação da realidade e, as entrevistas foram agendadas segundo a conveniência do colaborador, em local e data por ele marcados e após sua assinatura no Termo de Consentimento Livre e Esclarecido. Foram usadas perguntas dirigidas apenas para clarificar a narrativa. As entrevistas ocorreram em julho e agosto de 2003.

Nesse trabalho conseguiu-se unir duas coisas muito importantes para a elaboração: um indivíduo que se expressa de forma clara, tem alto nível de conhecimento sobre a patologia que o acomete e se dispôs a participar de uma pesquisa caracterizada pelo fato de o depoente poder revelar sua história à sua maneira e conduzir a entrevista, revelando o que lhe é mais importante frente a sua patologia.

Após a transcrição de sua fala, o colaborador releu seu discurso e todas as sugestões feitas por ele foram aceitas antes da análise dos dados.

\section{DISCUSSÃO DOS DADOS}

A gravidade de uma patologia depende tanto dos recursos do indivíduo para enfrentar as tensões, como da duração e intensidade dessas tensões ${ }^{(20)}$. A caracterização de uma vivência do sujeito como traumática depende dos recursos que ele conseguiu desenvolver ao longo da vida e da intensidade do estímulo e/ou evento ao qual está sendo submetido. A emoção busca a expressão, por meio da linguagem, para solucionar o estado de necessidade e obter satisfação. No entanto, se esse processo for total ou parcialmente bloqueado, a solução não é adequada, a ação mostrase comprometida e a emoção fica contida, o que implica que a manifestação da emoção fez-se de forma indireta e/ou simbólica. Aproximamo-nos, nesse momento, do conceito de somatização. Ainda segundo esse mesmo autor, teríamos no fenômeno psicossomático uma situação real de perda ou equivalente ou ainda uma representação imaginariamente presa a uma cena de perda, em particular o destino dado ao afeto, que lhe corresponderia e que é impossível ser vivenciado, a supressão, e uma clivagem do ego que permitiria a coexistência com outras defesas e estruturas de articulação de pulsão ${ }^{(3)}$. (Já a minha história com Crohn começou quando eu tomei pau no doutorado, aos 31 anos em 1991... ). 
O abdome é a caixa de ressonância das emoções. $\mathrm{O}$ trato gastro intestinal é filogeneticamente o sistema mais velho do corpo, e daí ser muito usado para expressar emoções que não se podem expressar pelas vias regulares ${ }^{(16)}$.

O sistema digestório é o responsável pela captação do ambiente de elementos necessários a nossa sobrevivência e de sua transformação em substâncias prontamente utilizáveis por nós. Os alimentos que o homem ingere proporcionam substâncias necessárias para a manutenção do metabolismo orgânico e fornece nutrientes para as atividades desenvolvidas pelo organismo. A absorção das substâncias alimentícias pelo organismo ocorre após sua transformação em constituintes mais simples e solúveis. Isso se dá por processos mecânicos e químicos denominados digestão, nos quais existe a interferência de mecanismos nervosos e hormonais ${ }^{(6)}$.

O processo digestório pode ser comparado ao sistema respiratório, já que é através da respiração que captamos o ambiente ao nosso redor e o assimilamos (inspiração), e tudo aquilo que não nos será necessário é devolvido (expiração). A respiração é regida pelo elemento ar, enquanto que a digestão pertence ao elemento terra, condição essa que lhe confere uma dinâmica mais material ${ }^{(6,17)}$.

Em comparação com as atividades mentais, que através do cérebro ou consciência recebe e digere as impressões imateriais do mundo, a digestão tem uma relação mais profunda com a dimensão material do corpo. A digestão abrange a captação das impressões materiais do mundo, a discriminação do que é suportável ou não, da assimilação dos materiais benéficos e expulsão dos indigeríveis. Ela está relacionada à razão e ao processo usado de forma racional para digerir o que vem de fora, ou seja, a forma como lidamos com situações concretas.

Eu acho que eu não tinha estresse antes do Crohn, dessa maneira não precisava descarregá-lo. Essa é uma coisa curiosa. Da mesma maneira que eu acho que eu não tive adolescência, eu não tive estresse. É engraçado que a experiência sensitiva é uma coisa que surgiu bem depois para mim, antes eu não sabia o que era isso, achava que era tudo invenção. Também nunca tive outras manifestações de dor ou desconforto, nunca quebrei um braço ou uma perna, sempre fui muito saudável. Eu sempre fui pouco observador para as coisas. Eu não sei onde eu focava as minhas atenções e gastava as minhas energias. Era um mundo de coisas que depois eu fui perceber que eu não via.

No intestino delgado ocorre a verdadeira digestão dos alimentos, através de um processo de divisão dos mesmos em seus elementos componentes (análise) e sua possível assimilação. Portanto, quando nos deparamos com moléstias no intestino delgado, devemos atentar para a possibilidade de estar envolvido um importante componente analítico, pois a função deste órgão é analisar, separar em partes, verificar os detalhes. Ele também indica um medo excessivo da sobrevivência, de não conseguir aproveitar bem e morrer de fome, já que é lá que eles são aproveitados ${ }^{(6)}$.
A diarréia é um sintoma comum associado ao intestino delgado, e está ligado a problemática do medo (ele está cagado de medo, está se borrando de medo). Quando temos medo, não sobra tempo para análise das impressões, e assim a expelimos sem serem digeridas. Assim sendo, nos retiramos para um lugar tranqüilo e agradável, onde podemos deixar os acontecimentos seguirem seu curso. Com isso, há perda de líquido que dá flexibilidade necessária para expandir e transpor as fronteiras do eu que nos infundem medo e causam sensação de aperto ${ }^{(6)}$.

No intestino grosso há finalização da digestão, com a absorção da água que restou nos alimentos digeridos. A psicanálise interpreta a defecação como um ato de doação e generosidade, e o excremento tem relação simbólica com o dinheiro. Se o intestino delgado corresponde ao consciente analítico, o intestino grosso corresponde ao inconsciente, no sentido literal ao submundo, e as fezes são conteúdos do inconsciente. Quem teme perder a vida, ou afirmar a própria personalidade, perde sangue e muco. São pessoas grudentas, pegajosas, que têm necessidade de se fazerem boazinhas e, dessa forma, renunciam da sua própria personalidade e vivem em função do outro.

Uma vez um cara pegou uma moça lá na estrada, na Dutra, e levou para a casa dele, daí todos os outros foram para lá para dormirem com a moça. Eu não fui, por que eu tinha os meus valores, e isso para mim não era plano;

Eu carrego comigo a culpa de não ter tratado bem a minha mãe. A gente vai conversando aqui e as coisas vão clareando. Eu me confesso com certa freqüência em relação ao $4^{\circ}$ - mandamento, que é honrar pai e mãe, então eu sinto uma dor por uma coisa que fiz, que foi tratar mal a minha mãe. Me lembro que eu e a minha irmã estávamos, certa vez, brincando com o meu pai, e num dado momento ele ficou bravo e falou: mais respeito com o seu pai! Daí eu vi como isso é sério. Nossa..., pai e mãe é sério. Hoje em dia eu me confesso mais pela omissão. Em casa eu defendo muito a minha mãe. Eu penso que eu fiz coisas próprias da minha adolescência, e ela falou coisas que ela achou que deveria falar;

Um deles (amigo) me chamou para ir ao "desabafo", e eu perguntei o que era, e perguntei para um amigo se lá era um ambiente familiar. E ele me respondeu que até às seis e meia era, mas que depois... Daí eu falei, então você não me convida mais para esses lugares. Então, eles ficaram com esse estigma. Então as pessoas param de falar algumas coisas quando eu chego. Elas não vêm falar muita besteira para mim. Não ficam falando mal dos outros, não dou muito ouvido para algumas coisas.

Viver a própria vida exige que, em determinadas situações, assumamos uma posição contra os outros, o que traz certa solidão, e é disto que a pessoa que sofre de colite tem medo, já que temendo a solidão, não consegue imaginar-se sem a aprovação das pessoas ao seu lado. Assim, sacrifica através dos intestinos (inconsciente) os símbolos de sua própria vida: o sangue e o muco.

A minha história com o Chron começou quando eu tomei pau no doutorado, aos 31 anos, em 1991. E isso eu tenho 
bem claro, já que essa foi minha primeira grande decepção. Até então, eu sempre tinha sido vencedor, essa foi minha primeira grande derrota, e vejo hoje que foi a derrota que de certa maneira tive que assumir sozinho....;

Querendo ou não, eu percebo que tem muita gente que me quer bem, isso é bom, mas em alguns momento de crise, Chron, dor e tudo mais, é difícil. Por que eu me sinto na obrigação da dar ouvido as pessoas, e elas às vezes têm opiniões diferentes. E isso me confunde. Aí eu gosto de fazer uma analogia: se você está caindo da montanha, rolando, bate pedra nas costas, arranha o corpo, e as pessoas falam: faz isso, faz aquilo, mas eu tô caindo, tentando me segurar em algum lugar...

Pacientes psicossomáticos apresentam uma característica que se traduz na dificuldade de descrever suas emoções e mesmo senti-las (alexitimia). Portadores de pensamento operatório têm o mundo interno pobre e investem intensamente na realidade externa, da qual passam a ser dependentes ou hiperadaptados. A dificuldade de cuidar de si mesmo decorre do fato de, quando criança, viver como transgressão, e sujeito a castigo, o ato de interiorizar o objeto materno com o propósito de adquirir funções protetoras e tranquilizadoras ${ }^{(6)}$.

Depois disso, a minha mãe me chamou no quarto e me repreendeu pelo fato deu ter dito aquilo às suas amigas. Pedi muitas desculpas... foi a última vez que chorei. A partir daquele dia ela disse que não mais lavaria as minhas roupas. Passei a me virar sozinho.

Os sintomas das doenças intestinais podem eclodir diante de situações que, para a pessoa, envolvam ou reportem estresse, como a necessidade de maior independência, aumento de responsabilidade, esforço e concentração ${ }^{(\mathbf{1 1 1})}$.

Talvez tenha sido um pouco antes, naquele estresse que eu estava passando, e também quando eu recebi algumas notícias de que culminaria com a reprovação, daí desencadeou mais forte a doença.

Ao estabelecermos uma relação afetiva baseada em padrões simbióticos, só nos sentimos satisfeitos quando estivermos juntos a outra pessoa. Qualquer objetivo será considerado atingido, desde que se estenda ao outro. Quem sofre de colite não se permite ser o que é. Por medo da solidão anula-se diante dos relacionamentos, apenas para não ferir as pessoas com as quais se relaciona ${ }^{(17)}$.

Como ministro aulas no primeiro e segundo semestres do primeiro ano, os alunos que deixaram de ser meus alunos, propriamente dito, ou viram amigos, ou colegas. Eles podem bater em mim, e batem de verdade, batem mesmo, mas não tem problema, é adolescente, bate pelas costas, depois esquece;

O relacionamento interpessoal sempre foi um problema, porque eu sempre fui muito aberto com as pessoas, falava tudo, e quando as pessoas me escondiam, quando tinha essa maldade com as coisas, isso me matava.
Nos doentes psicossomáticos a função onírica (sonhos e devaneios), importante no processo de simbolização que dão vazão as tensões internas, encontram-se alteradas e aparecem juntamente com o aparecimento do pensamento operatório, que caracteriza um modo original de relação de objeto, em que o paciente expõe suas perturbações como fatos isolados, sem nenhuma relação aparente. As associações se apresentam ligadas apenas à materialidade dos fatos e dentro de uma relação temporal limitada. Eles se diferenciam dos demais pela pobreza do mundo simbólico. Sonham pouco e seus sonhos são realistas. Há pouca elaboração psíquica, sendo seu pensamento do tipo operatório, aprisionado no concreto. Por ter pouca interação com seu inconsciente, frente a qualquer estresse, por incapacidade de simbolizar, reagiria com uma doença somática ${ }^{(3,11,18)}$.

\begin{abstract}
Aos 8 anos eu tive um acidente que resultou em queimadura. Então fiquei no hospital 14 dias em coma, e no total três meses e meio... Eu nem perdi o ano na escola. $O$ acidente foi em novembro, e eu me lembro que eu tinha notas muito boas, ganhava medalhinhas, cartões de $1^{\circ}, 2^{\circ}$ e $3^{\circ}$ lugares na sala. $\mathrm{E}$ o relacionamento com os colegas foi normal. Inclusive eu andava com um colarinho cervical devido às cirurgias plásticas no pescoço, estava tudo colado, estava colado o queixo no peito. Tiveram que fabricar um pescoço. Estudava comigo um garoto chamado José Luis. Um dia ele estava sentado do meu lado, e começou a bater o lápis na carteira. A professora achou ruim e pediu para que ele parasse, e de repente ele teve um ataque, sei lá, acho que uma convulsão. Ele sim, não era normal, eu sou normal....
\end{abstract}

Ligados apenas ao presente, o passado e o futuro se resumem em uma sucessão de fatos, destituída de associações. O paciente psicossomático não dá significado a ação, mas apenas a reproduz sem afetividade ${ }^{(18)}$.

O relacionamento com os outros foi normal. Eu só me lembro - eu já estava fazendo o mestrado - de um menino no ônibus que me olhava e passava a mão no rosto dele. Aí ele me perguntou o que você têm? Aí eu pensei que estivesse sujo o meu rosto, daí a mãe dele o puxou de perto de mim e eu nem consegui falar com o moleque. Mas isso nunca me afetou. Como eu sou meio tardo, muitas coisas devem ter acontecido e eu não percebi. Eu não me lembro de ter sido uma pessoa traumatizada por causa disso. Tem até algumas fotos dessa época, uma em especial eu tô muito deformado, deformado mesmo. Então eu olho para ela e penso passou, passou.

A patologia da psique, ou patologia da personalidade, começa desde a infância, mas permanece despercebida por muitos anos. A psique ou personalidade age como centro coordenador para conseguir aquelas imediatas satisfações e traçar planos para o futuro ${ }^{(16)}$.

O adulto alexitímico funciona como uma criança que depende da mãe para interpretar seus sentimentos e afetos. Observou-se em muitas situações que os pais criticam ou deixam dúvidas quanto ao afeto da criança, as vezes lhe 
indicam o que devem ou não sentir ou mesmo os proíbem de sentir (garotos não choram). A criança acaba se confundindo e fica sem saber o que pode ou não sentir ${ }^{(3)}$.

É problemático sustentar a existência de limites rígidos entre o normal e o patológico, uma vez que ambos se mesclam com vista a atingir a cada momento o equilíbrio psicossomático e a assegurar a vida do indivíduo. Toda reação normal apresenta também componentes desviantes ou desorganizados, assim como toda patologia é também composta de um mínimo de organização, para que a sobrevivência da pessoa seja possível ${ }^{(2)}$.

$\mathrm{Na}$ tentativa de obter maior objetividade nas investigações, diversos autores têm-se utilizado de testes psicológicos para avaliação de personalidade de portadores de doenças inflamatórias intestinais. Uma pesquisa utilizou o PFS (Rosenzweig Picture-Frustration Study), encontrando escores significantes relacionados a Intrapunitividade, ou seja, a tendência a direcionar os impulsos agressivos para si mesmos, inibindo-os em relação ao ambiente ${ }^{(\mathbf{1 1})}$.

Meu irmão mais novo nasceu por culpa minha...

Eu carrego comigo a culpa de não ter tratado bem a minha mãe...

Hoje eu vejo que eu sempre fui muito egoísta, que vivia no meu mundinho.

\section{REFERÊNCIAS}

1. Riechelmann JC. Medicina psicossomática e psicologia da saúde: veredas interdisciplinares em busca do "elo perdido". In: Angerami-Camon VA, organizador. Psicologia da saúde. São Paulo: Pioneira; 2000. p. 171-99.

2. Volich MR. Psicossomática. São Paulo: Casa do Psicólogo; 2000.

3. Mello Filho J. Psicossomática hoje. Porto Alegre: Artes Médicas; 1992.

4. Vasconcellos EG. Tópicos de psiconeuroimunologia. São Paulo: Ipê/IPSSP; 1998.

5. Vasconcellos EG. Bases psiconeuroimunológicas da intervenção em psicologia da saúde. In: Anais do $2^{\circ}$ Congresso Norte Nordeste de Psicologia; 2001 maio 23; Salvador [CD-ROM]. Salvador: Universidade Federal da Bahia; 2001.

6. Dethlefsen T, Dahlke R. A doença como caminho. São Paulo: Cultrix; 1983.

7. Pinotti HW. Tratado de clínica cirúrgica do aparelho digestivo. São Paulo: Atheneu; 1994.

8. Damião AOMC, Habr-Gama A. Retocolite ulcerativa idiopática. In: Dani R, Castro LP. Gastroenterologia clínica. $3^{\mathrm{a}}$ ed. Rio de Janeiro: Guanabara Koogan; 1993. p. 1037-76.

9. Smeltzer SC, Bare BG. Brunner \& Suddarth: tratado de enfermagem médico-cirúrgica. $8^{\mathrm{a}}$ ed. Rio de Janeiro: Guanabara Koogan; 1998.

\section{CONSIDERAÇÕES FINAIS}

É importante considerar que toda doença - mental, somática ou comportamental - apesar de seu caráter desviante e regressivo é, ainda, uma tentativa de estabelecimento de um equilíbrio do organismo, que não consegue enfrentar as tensões internas ou externas às quais está submetido por intermédio de recursos mais evoluídos ${ }^{(2)}$.

Por ser o corpo uma via de expressão de desajustes mentais no caso dos pacientes psicossomáticos, nos dá a possibilidade de trilhar o caminho corpo - mente quando nos referimos ao cuidar, auxiliando-o em uma maior percepção de si e conseqüente melhora em sua qualidade de vida.

A função terapêutica resgata uma experiência primordial que nos constitui: todos cuidamos. Mas, muitas vezes, implica numa tentativa de dizer o incomunicável e de compreender o incompreensível. Dor compartilhada, freqüentemente por nós negada, recusada, que remete cada um de nós a nosso desamparo mais fundamental: a necessidade de sermos também cuidados.

O Estudo da doença de Chron, por meio da compreensão psicossomática, permitiu que analisássemos os sintomas, não como corpos estranhos a ser erradicados, mas como mensageiros de um apelo a ser compreendido. Por intermédio deles, pode ser resgatada a história de um indivíduo. História esta que, se conscientemente vivida e analisada, permite o desenvolvimento até níveis mais evoluídos de entendimento e harmônicos de funcionamento da pessoa.

10. Teixeira MG, Habr-Gama A, Takiguti CK, Brunetti Netto C, Pinotti HW. Aspectos epidemiológicos da doença de Chron em 140 pacientes no serviço de coloproctologia do HCFMUSP. Rev Bras Coloproctol. 1993;13(4):201-13.

11. Pinto KO. Personalidade e qualidade de vida em portadores de doenças inflamatórias intestinais: subsídios para avaliação de paciente crônico em coloproctologia [dissertação]. São Paulo: Faculdade de Medicina, Universidade de São Paulo; 2001.

12. Guyatt GH, Van Zathen SJOV, Feeny DH, Patrick DL. Measuring quality of life in clinical trials: a taxonomy and review. Can Med Assoc J. 1989;140(15):1441-8.

13. Irvine EJ. Quality of life: rationale and methods for developing a disease - specific instrument for inflammatory bowel disease. Scand J Gastroenterol Suppl. 1993;(199):22-9.

14. Lima AFC, Gualda DMR. História oral de vida: buscando o significado da hemodiálise para o paciente renal crônico. Rev Esc Enferm USP. 2001;35(3):235-41.

15. Meihy JCSB. Manual de história oral. São Paulo: Loyola; 1998.

16. Weiss E. Medicina psicossomática: aplicação clínica da psicopatologia aos problemas da clínica em geral. Rio de Janeiro: Guanabara; 1996.

17. Odoul M. Diga-me onde dói e eu te direi porquê: os gritos do corpo são as mensagens das emoções. Rio de Janeiro: Campus; 2003.

18. Ramos DG. A psique do corpo: uma compreensão simbólica da doença. São Paulo: Summus; 1994. 